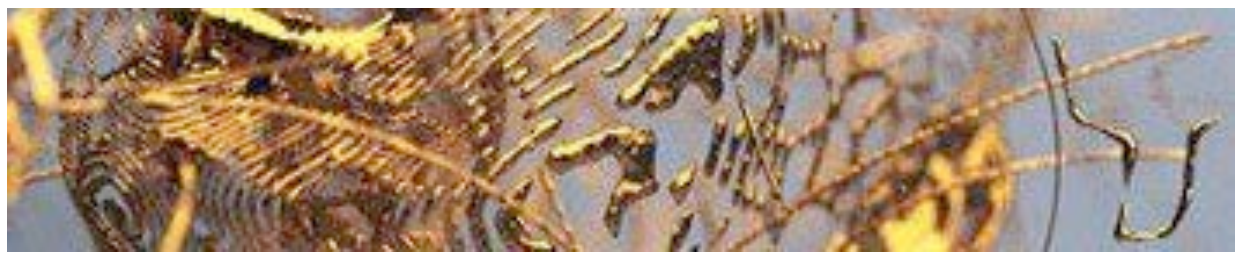

\title{
Cultura de Paz e Mediação Social. Fundamentos para a construção de uma sociedade mais justa e participativa
}

\section{Culture of peace and social mediation. Founda- tions for building more just and participatory society}

\author{
Helena Neves Almeida ${ }^{(*)}$
}

Universidade de Coimbra - Portugal helena.almeida@,fpce.uc.pt

Cristina Pinto Albuquerque ${ }^{(* *)}$ Universidade de Coimbra - Portugal crisalbuquerque@fpce.uc.pt

Clara Cruz Santos ${ }^{(* * *)}$

Universidade de Coimbra - Portugal clarasantos@,fpce.uc.pt

Resumo

Quando os laços sociais se degradam e de forma crescente têm maior expressão problemas de pobreza, exclusão social e institucional e violência, a mediação social
Abstract

When social bonds increasingly degrade, problems such as poverty, social and institutional exclusion and violence increased expression and, in this context, 
revela especial importância. São necessárias novas e inovadoras respostas para problemas e conflitos antigos ou emergentes no mundo contemporâneo, onde imperam a complexidade, a incertez a e o risco social. O presente artigo produz uma análise crítica e reflexiva sobre o significado multidimensional da paz e os valores em confronto em contextos plurais. Explora ainda o contributo inovador da mediação para construção de uma sociedade mais justa e participativa e para a promoção de uma Cultura de Paz.

Palavras-chave: Mediação Social, Cultura de paz, Participação, Justiça Social social mediation reveals special importance. New and innovative answers to old and emerging problems and conflicts in contemporary world, where prevails the complexity, uncertainty and social risk, are required. This article shall take a critical and reflective analysis on the multidimensional meaning of peace and the values found in plural contexts. Also explores the innovative contribution of mediation to building a more just and participatory society and to promote a Culture of Peace.

Keywords: Social Mediation, Culture of Peace, Participation, Social Justice 


\section{NOTA INTRODUTÓRIA}

O desenvolvimento de lógicas divergentes a nível social, cultural, económico e político, provocam dinâmicas conflituais que impulsionam guerras, intolerâncias, a banalização da destruição e da desvalorização do capital humano e social. O limiar do século XXI (1999) é prodigo em declarações e manifestos de organizações internacionais, apelando ao desenvolvimento de uma Cultura de Paz: A Assembleia da Unesco declara que a "Cultura da Paz é um conjunto de valores, atitudes, tradições, comportamentos e estilos de vida baseados no respeito à vida, ao fim da violência, à prática da não-violência por meio da educação, diálogo e cooperação", e em 4 de março de 1999 foi lançado o manifesto 2000 por uma Cultura de Paz e Não violência, elaborado por personalidades laureadas com o Prémio Nobel da Paz conjuntamente com as Nações Unidas e a UNESCO. Reconhecendo-se o efeito destrutivo dos conflitos a nível internacional impera, deste modo, o desiderato de desenvolvimento de uma cultura de paz, afirmado pelas Nações Unidas (1999), que promova o bem-estar social, o desenvolvimento sustentável e o respeito pelos Direitos Humanos.

Derivada do latim, a palavra Paz enquadra um sentido ambivalente. Se, por um lado, o conceito se associa à noção de Pacem = Absentia Belli, ou seja, à ausência de violência, à isenção de ira, desconfiança e de todos os sentimentos negativos, por outro lado, a noção de Paz ultrapassa largamente essa aceção para se associar sobretudo a uma ideia de processo, de construção de valores e de pactos de progresso e conexão, que permitam uma vivência coletiva marcada pela justiça, pela liberdade e, como tal, pelo respeito pelas diferenças e pelos contributos de todas as pessoas e de todos os povos. Esta dimensão é sublinhada pelas Nações Unidas, quando definem, nos termos da Declaração para uma Cultura de Paz, que "o progresso no sentido do completo desenvolvimento de uma cultura de paz é conseguido através de valores, atitudes, comportamentos e estilos de vida que conduzam à promoção da paz entre indivíduos, grupos e nações" (Resolução 52/243 da Assembleia Geral das Nações Unidas, de 6 de Outubro de 1999, Artigo $2^{\circ}$ ).

Porém, a paz não está confinada a fronteiras histórica, política e administrativamente definidas, ela incorpora dimensões com relevância a nível pessoal, interpessoal e societal. Ainda de acordo com o mesmo documento (Artigo $3^{\circ}$ ), o pleno desenvolvimento de uma cultura de paz agrega diferentes dimensões inter-relacionadas, nomeadamente: A promoção da resolução pacífica dos conflitos, do respeito e entendimento mútuos e da cooperação

Mediaciones Sociales, № 12, 2013, pp. 132-157. ISSN electrónico: 1989-0494.

DOI: http://dx.doi.org/10.5209/rev_MESO.2013.n12.45266 
internacional; O cumprimento das Obrigações Internacionais; A promoção da democracia, do desenvolvimento e do respeito pelos direitos humanos e liberdades fundamentais; $O$ desenvolvimento de capacidade de diálogo, negociação, criação de consensos e resolução pacífica das diferenças; $\mathrm{O}$ reforço das instituições democráticas e garante da plena participação no processo de desenvolvimento; A promoção do desenvolvimento económico e social sustentável; A eliminação de todas as formas de racismo, discriminação racial, xenofobia e outros tipos de intolerância; A erradicação da pobreza, do analfabetismo e das desigualdades sociais; O respeito, a promoção e a protecção dos direitos da criança; $O$ garante da livre circulação de informação e promoção da sua acessibilidade; $\mathrm{O}$ aumento da transparência e da responsabilização na gestão dos assuntos públicos; A promoção da compreensão, da tolerância e da solidariedade entre civilizações, povos e culturas; a criação de mecanismos capazes de agir, de forma curativa e preventiva, nos conflitos emergentes. A extensão de tais dimensões (Figura 1) coloca em evidência a necessidade de reflectir e agir de forma coordenada e concertada através de processos de regulação social e de transformação das lógicas conflituais em padrões de desenvolvimento global.

Figura 1. Cultura de paz e dimensões éticas da vida social

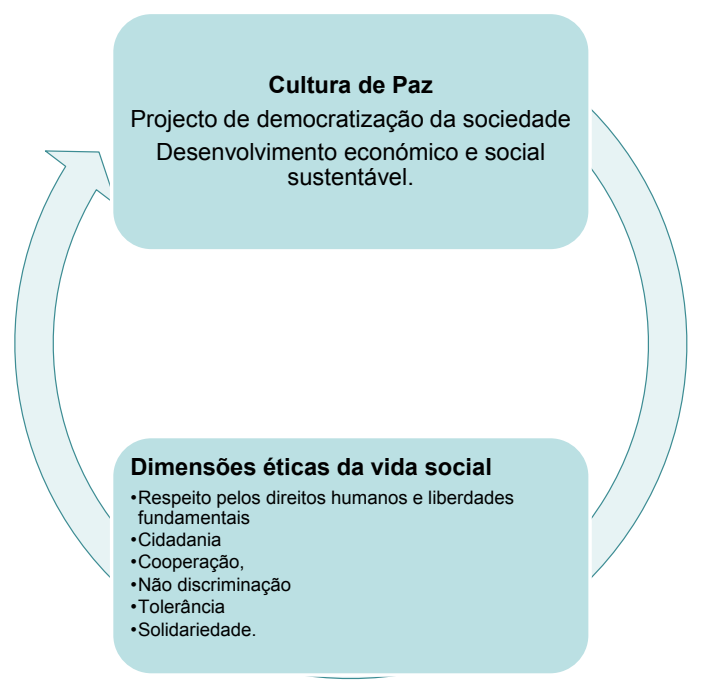

Pugnar por uma cultura de paz é pois muito mais do que defender a via de resolução pacífica de conflitos, o que nos permite discutir as possibi- 
lidades de agregação entre uma cultura de Paz e uma cultura de mediação. Uma cultura de mediação que permita não somente resolver/ prevenir pacificamente conflitos mais ou menos micre delimitados (em consonância com uma prática mais tradicional e restrita associada à mediação), mas também perspectivar a importância e as potencialidades de uma mediação de cariz mais político, social e comunitário que permita consubstanciar condições de desenvolvimento e de democracia mais substantivas e emancipadoras para grupos populacionais mais abrangentes e em menos casos em situações de vulnerabilidade e de opressão.

A cultura de paz inscreve-se com efeito num projeto mais amplo de democratização da sociedade com respeito pelas diferenças e promoção de maior justiça social, a que se associa um desenvolvimento económico e social sustentável. Uma sociedade assim compreendida integra dimensões éticas da vida social, como o respeito pelos direitos humanos e liberdades fundamentais, a cidadania, a cooperação, a não discriminação, a tolerância e a solidariedade. Uma cultura de paz traduz-se, deste modo, num devir ético, político e social, um processo em desenvolvimento e em permanente construção, capaz de transformar o potencial negativo, associado ao terrorismo, à insegurança, à desigualdade, à desconfiança e à intolerância, numa dinâmica de sinergias abertas à mudança. Por tais razões, seria desejável a sua expansão aos mais diversos contextos, documentos e discursos que reflectem simbolicamente a vida em sociedade e as relações que dela emergem.

Na senda desta reflexão, o presente artigo pretende discutir, inicialmente, as dimensões constituintes do conceito de Paz, com reforço para os seus aspectos éticos para, num segundo momento, caracterizado pela correlação analítica entre o conceito de Mediação e o conceito de Paz nos posicionarmos criticamente sobre a forma como a Mediação pode e deve servir de instrumento estratégico de gestão social e de potenciação da democratização da sociedade actual.

\section{O Projecto Ético, Político e Social da PAZ}

O projecto ético-social da paz preconiza que este conceito se estenda para além da simples ausência de conflito. A paz, entendida como âncora e produto de desenvolvimento, pressupõe a possibilidade e a capacidade de ser livre. Direitos Humanos, Liberdade, Tolerância e Justiça Social são dimensões incontornáveis à compreensão da Paz, que se constitui como 
um dos Direitos Humanos consagrados na Declaração Universal. Consideramos, no entanto, necessário re-discutir conceitos que, devido a uma constante utilização, podem servir muitas vezes de base justificativa a acções distintas e contraditórias, e, como tal, ficam vazias de conteúdo, perdendo consistência teórica, ideológica e pragmática.

A noção de Direitos Humanos é uma dessas noções, e isto confronta-nos incontornavelmente com o défice de reflexão ética e política que tende a caracterizar as sociedades actuais. A permanente referência aos direitos humanos, explicita uma metanarrativa em desagregação, ou um conteúdo excessivamente impreciso e manipulável. Com efeito, a tendência para um discurso minimalista e mediático, o predomínio do hedonismo e da circunstancialidade (sobretudo das agendas político-ideológicas), tem colocado em segundo plano um debate profundo e necessário. Os direitos humanos, com todas as declarações, tratados e convenções que procuraram consubstanciá-los, são uma referência ética basilar e o produto de um percurso civilizacional, iniciado na época clássica. No entanto, face às condições paradoxais da era actual, onde as desigualdades sociais se aprofundam e as oportunidades se centralizam em pressupostos económicos e políticos de gestão do poder, começa a evidenciarse a necessidade de questionar: $\mathrm{O}$ que se entende por direitos universais e inalienáveis, inerentes à natureza humana? Que consenso é possível ainda destacar? A questão de base, implica uma reflexão sobre os fundamentos do nosso projecto humano, superando a nossa tranquilidade pela mera consagração de tais direitos numa tábua de mandamentos, e aceder aos fundamentos éticos da mesma: a essencialidade do ser humano.

Aquilo que pode traduzir-se, num conceito de dignidade humana, ao mesmo tempo simplista e complexo, consubstancia-se, assim, na articulação entre a vida e a liberdade. Sempre que a vida se transforma em mera sobrevivência, ou se encontra colocada em causa a verdadeira capacidade de escolha e de afirmação de si, - devido a factores como a fome; as guerras; os totalitarismos; as perseguições, entre outros, - a dignidade humana é colocada em causa. Isto significa que não podemos ser transigentes com as estratégias de legitimação de práticas de indignificação humana, invocando motivos étnicos, religiosos, geográficos, culturais ou ideológicoutilitaristas assentes na pretensa busca de um "bem maior". Na reflexão sobre Direitos Humanos a polémica entre universalistas e pluralistas é superada se considerarmos que os direitos se concretizam em contexto consagrando a opção política em prol da igualdade, da liberdade e da paz-, mas que não podem deixar de partir de um mesmo pressuposto universal: 
todos os seres humanos têm direito à dignidade. Os Direitos Humanos não podem, pois, depender de factores contingentes como a etnia, o género, as opções políticas, religiosas, culturais, sexuais ou o reconhecimento político da cidadania. Não é a cidadania que é a base dos direitos humanos, são os direitos humanos que se constituem como a base da cidadania.

Neste sentido, o discurso da tolerância pode facilmente transformar-se no discurso da resignação, da permanência na impossibilidade. Na verdade, a afirmação da igualdade fundamental é, por outras palavras, a possibilidade de comportar, reconhecer e respeitar as diferenças. Sublinhe-se que este pressuposto de respeito pela diferença, porque parte do reconhecimento do valor e dignidade humana, anulando, pois, qualquer forma de discriminação, tem contornos universais. A existência de tratados e organizações internacionais (ONU) não são mais do que a tradução pública de emoções sociais partilhadas, de orientação para o outro e de preservação da paz.

Na afirmação de Vinyamata, na apresentação do livro de Farré Salvá Gestión de los conflictos: taller de mediación. Un enfoque socioafectivo,

"la paz no es la paz de los muertos, no surge de la inexistencia de problemas, ni de la negación de los conflitos, ni desde la ausencia de esfuerzos por vivir en armonia surge, justamente, de la superación de los mismos, de su transcendencia. La paz no es unicamente un estado el cual algunos paises saben construir y otros se muestram incapaces de ello. La paz tambén es aquella capacidad de las personas de encontrar solución a sus problemas sin prejudicar, la capacidad de convivir desde la diferencia, de colaborar desde la discrepancia, la capacidad que se adquire de aproximarse a la felicidad sin necessidad de arrebatarla" (Farré Salvá, 2010:13).

"Falamos muito de paz, mas para que a paz exista tem de haver uma atmosfera conciliadora. Temos de criar essa atmosfera e para o fazermos temos de gerar a atitude correcta. A Paz tem de começar a vir de nós mesmos. E porque havemos nós de procurar a paz? Pela simples razão de que a paz nos beneficia a longo prazo, e por conseguinte, a desejamos" (Segundo Dalai Lama, 2002: 56).

A construção da justiça e a visibilização das injustiças é, neste sentido, obrigação de todos e de cada um, e é esta componente de complexidade e de solidariedade (leitura ecológica do mundo) que corre hoje riscos de ruptura e que deve ser reafirmada num debate complexo e profundo sobre a condição de humanidade. Por outras palavras, trata-se de interiorizar duas ideias: 
a) Todos os seres humanos se diferenciam, mas não têm de ser desiguais. A diferença é do domínio da essência, a desigualdade é uma construção social e como tal pode ser questionada e superada.

b) Todos somos responsáveis por todos. A tragédia do outro é também a nossa tragédia.

As mesmas ideias são expressas no Manifesto da UNESCO para uma Cultura de Paz e de Não Violência (2000) ao reconhecer que só uma cultura de Paz torna possível um desenvolvimento duradouro, a proteção do meio ambiente e a satisfação pessoal de todos os seres humanos. Numa ótica de responsabilidade partilhada, iniciada na esfera individual mas consubstanciada num projeto necessariamente transdisciplinar, consagram-se como princípios nucleares do Manifesto (escrito por um conjunto de Prémios Nobel da Paz):

-o respeito pela vida e a dignidade de cada ser humano, sem discriminações ou preconceitos; -a prática da não violência ativa, combatendo a violência em todas as formas que pode assumir (física, sexual, económica e social), em particular para com os mais débeis e vulneráveis; -a partilha do próprio tempo e dos recursos materiais, cultivando a generosidade a fim de acabar com a exclusão, a injustiça e a opressão política e económica; -a defesa da liberdade de expressão e da diversidade cultural, privilegiando sempre a escuta e o diálogo; -a promoção de um consumo responsável e de um modo de desenvolvimento que considere todas as formas de vida e o equilíbrio de recursos naturais do Planeta; -a contribuição para o desenvolvimento das próprias comunidades, propiciando a plena participação das mulheres e o respeito pelos princípios democráticos a fim de criar novas formas de solidariedade.

Os grandes debates internacionais em torno da Paz na actualidade reconhecem-na pois de forma inequívoca como uma âncora e um produto de desenvolvimento a todos os níveis - pessoal, social, político, económico e cultural. A paz não é vista apenas como uma fase no tempo ou como uma condição; é um processo social dinâmico, e como tal, requer um processo de "construção", que implica investimento, materiais, desenho arquitectónico, coordenação do trabalho, colocação dos materiais e trabalho de acabamento, além de uma manutenção contínua. 
Nesta perspetiva, a mediação pode constituir-se como mecanismo estruturante do processo de construção de que fala o autor, na medida em que, sobretudo na sua feição de mediação social e comunitária, permite, não só colocar em interação partes (pelo menos aparentemente) desconexas e questionar (ou visibilizar) as relações de influência e poder que lhes subjazem em prol de um trabalho conjunto e da celebração de pactos, mas também criar as condições para a conquista, por parte de indivíduos, grupos e comunidades de estruturas de oportunidades necessárias ao seu desenvolvimento substantivo e à consequente capacitação e liberdade.

\section{Cultura de Mediação E CUltura de PAZ: ReFerenciais ANA- LÍTICOS DA E NA INTERVENÇÃO SOCIAL}

Os conflitos e os problemas constituem uma componente fundamental da vida humana em sociedade (Fonkert, 1999: 170) e, pelo seu carater transformador (Folger e Bush, 1999: 85), impulsionam mudanças e transformações, que têm permitido aos seres humanos a conquista de novas realidades, e configuram ainda oportunidades de crescimento e desenvolvimento a nível individual e societal . O conflito resulta inevitavelmente da interação, uma das formas básicas das relações sociais, que pode assumir um efeito destrutivo ou, pelo contrário, contribuir para a definição de identidades e racionalização de estratégias de cooperação e competitividade. A análise do conflito requer, por isso, que se procurem nós de inteligibilidade sobre a origem do litígio, a natureza, o continuum e o estado da relação entre os intervenientes na ação, e ainda, sobre o significado que o mesmo tem para cada uma das partes. Identificar o âmago e os nós das interações existentes ou ocorridas implica muito mais do que uma simples sinalização. É imprescindível compreender os contextos e os significados atribuídos pelos sujeitos da ação, na medida da proximidade possível. Não se trata apenas de identificar, mas (re)construir conexões entre a natureza do conflito, os episódios significativos para os sujeitos e os significados que lhes são atribuídos em contextos específicos.

O projecto de paz que temos vindo a assinalar não adquire apenas relevância a nível internacional, ele ganha expressão instrumental em cada nação, a nível local, comunitário, social, interpessoal e pessoal. É neste contexto que o conceito e as práticas de mediação adquirem visibilidade e importância. 
Independentemente do paradigma que seja adoptado, no âmago da intervenção social coexiste sempre o reconhecimento de um conflito, transformado em problema, ou de um problema transformado em conflito. As visões funcionalistas identificam o conflito como algo negativo, mas estudos aprofundados baseados em evidências empíricas vieram revelar que o conflito não é necessariamente negativo, deve surgir e seguir o seu próprio curso, ainda que não em proporções de tal forma graves, que comprometam o desenvolvimento e a integridade do ser humano. De certa forma o conflito pode ser o valor comunicacional de um problema bloqueador do crescimento ou desenvolvimento social. Nesta assunção, a sua expressão evita a rigidificação de práticas sociais não adequadas aos contextos em questão. Desta feita, abriu-se a possibilidade de trabalhar o conflito com uma visão diferente, não o prevenindo para evitar que surja, mas trabalhando-o para diminuir a sua escala, estimulando as relações colaborativas e cooperativas, dando corpo à concepção de mediação como instância de provenção e não de prevenção de conflitos.

"Provenção de conflitos significa deduzir, a partir de uma explicação adequada do fenómeno do conflito - incluindo as suas dimensões humanas -não só as condições que criam um ambiente de conflito e as mudanças estruturais requeridas para o remover, mas, mais importante, a promoção de circunstâncias que criam relações cooperativas" (Burton, 1990: 3, in Torremorell, 2003: 38).

É hoje consensual que a mediação é um processo de intervenção onde a transformação social está presente, implicando a melhoria das relações humanas - viver, estar e relacionar-se melhor. Nesta perspectiva enquadramos a melhoria das competências de comunicação, com a criação de relações de empatia, das sociabilidades, implicando a participação, activa, das pessoas e o seu empowerment.

\subsection{Dinâmicas concetuais de mediação social}

A mediação, inicialmente entendida como um modo alternativo à tradicional resolução judicial de conflitos entre particulares e entre estes e os serviços públicos, expandiu-se, a partir de meados dos anos 70, com as abordagens sociológicas, a "um modo de regulação social" (BonaféSchmitt, 1988, 1992a). No domínio social e comunitário, tal aceção ganha maior expressão, sendo as boutiques de droit e as community boards exemplos de experiências desenvolvidas. 
As boutiques de droit, associações de informação jurídica, surgiram em França (1975) por iniciativa de advogados e militantes associativos. Instalaram-se nos bairros para dar resposta à procura social das populações mais desfavorecidas e facilitar-lhes o acesso ao "direito a ter direitos", e o seu domínio de acção é o contencioso do quotidiano, a regulação de litígios menores, como por exemplo pequenos furtos, querelas verbais, maus cheiros na via pública. O projecto de mediação sobre o qual as "boutiques de droit” assentam, baseia-se na criação de estruturas de proximidade e na implicação activa dos habitantes. Por tudo isto, Bonafé-Schmitt (1992b) considera a mediação uma justiça doce. Nos termos da "Carta da mediação e das boutiques de droit" (Turrel, 1995, in Six, 1995: 147) o conceito aparece como precursor de um direito de ingerência social de certos actores da sociedade civil, direito que daria legitimidade aos habitantes dos bairros designados como mediadores.

"Le choix d'action des Boutiques de Droit procède d'un droit d'ingérence sociale de certains acteurs de la Société Civile qui permettrait à des habitants des quartiers, désignés comme médiateurs, d'être porteurs d'une certaine légitimité" (Turrel, 1995: 8).

No que respeita às Community Boards, a mais conhecida é a de San Francisco, que funciona independente dos tribunais e foi criada em 1977 por Ray Shonholtz, um professor de direito que se mostrava insatisfeito e decepcionado com a lentidão das decisões judiciárias. Esta iniciativa visava inicialmente humanizar o tecido social em que se manifestavam conflitos interpessoais e implicar cada cidadão através da sua responsabilização na procura de uma solução para as divergências quotidianas. $O$ clima de confiança consolidado permitiu dar voz aos conflitos existentes, tendo sido criado um espaço onde as pessoas podiam falar dos seus problemas e resolvê-los com a ajuda de terceiros e de forma extra-judicial. Nesta perspectiva, a mediação foi também entendida como uma acção preventiva da marginalidade (Verin, 1988: 201-206). O trabalho de base consistia no estabelecimento de contactos com a população e com as instituições. A experiência de San Francisco é diferente de outros modelos de mediação, uma vez que: a) a mediação é concebida como um meio de solucionar assuntos penais, numa perspectiva de prevenção de criminalidade, e b) visa a regulação pacífica de conflitos menores pela revitalização do espírito comunitário nos bairros urbanos. Neste contexto, a mediação ultrapassa a resolução de conflitos: os cidadãos procuram a paz social pela redução de tensões sociais e raciais, pelo desenvolvimento de solidariedades, pela prevenção de confli- 
tos de vizinhança. Neste caso, a mediação é uma incitação cívica e pessoal pela informação, educação e acção.

No âmbito desta perspectiva, o conceito de laço adquire relevância social e política, e com ele o conceito de mediação ganha uma dimensão estratégica no processo de intervenção. "O laço social não é um facto; é sim uma categoria” (Leandro, 2011:31) analítica da vivência dos homens em sociedade. Objecto de pesquisa de diversos sociólogos, de onde se destacam Emile Durkheim, Max Weber e George Simmel, a sua construção conceptual demonstra que "o conjunto das relações sociais que agregam os indivíduos entre si, estruturam-se num ordenamento de que é possível apreender os seus fundamentos, tanto a nível micro social (as interacções), como macro social (a coesão)" (ibidem). Por isso, a abordagem teórica e operativa das circunstâncias de vida em sociedade não se pode alhear da importância da interacção na construção e compreensão dos factos sociais e interventivos, como a pobreza, o desemprego ou a exclusão social. A ruptura, a consolidação ou a reconfiguração de laços sociais constitui um desafio incontornável dadas as suas implicações na coesão social e identidade (pessoal e social). A divergência de interesses, de atitudes e comportamentos está genericamente associada à emergência de conflitos, que sendo importantes num processo de desenvolvimento pessoal ou social, se tormam preocupantes quando se associam a rupturas de laços e a comportamentos disruptivos, ou que coloquem em causa a coesão social. Este é um dos motivos porque a intervenção mediadora de uma terceira pessoa (o mediador), exterior à dinâmica conflitual, se mostra relevante do ponto de vista, não apenas pessoal, mas também social e político.

Não se reduzindo apenas à resolução de conflitos, e à inerente associação à crise judicial de regulação de litígios, a mediação em contextos de pluralidade social e cultural passa a ser considerada "uma estratégia fundamental na perspectiva do reforço do diálogo intercultural e da coesão social.” (Oliveira e Galego, 2005: 25). Esta perspectiva avança que a mediação

"mobiliza um projecto de restauração de laços sociais, sustentando modalidades alternativas de gestão das relações sociais, tornando-se um processo comunicacional de transformação do social e uma requalificação das relações sociais" (ibidem, 26).

A mediação é, pois, um recurso cada vez mais utilizado e que permite 
"incluir os diferentes participantes num conflito, promove a compreensividade; ao aceitar diferentes versões da realidade, defende a pluralidade; e ao fomentar a livre tomada de decisões e compromissos, contribui para a participação democrática” (Torremorell, 2008: 8).

Para este autor, a ideia de transformação surge associada ao valor social que a mediação produz e à mudança social que provoca (Figura 2), considerando as dimensões relacionais do ser humano (ibidem: 70-77):

Figura 2. Concepções de mediação no quadro das dimensões relacionais do ser humano

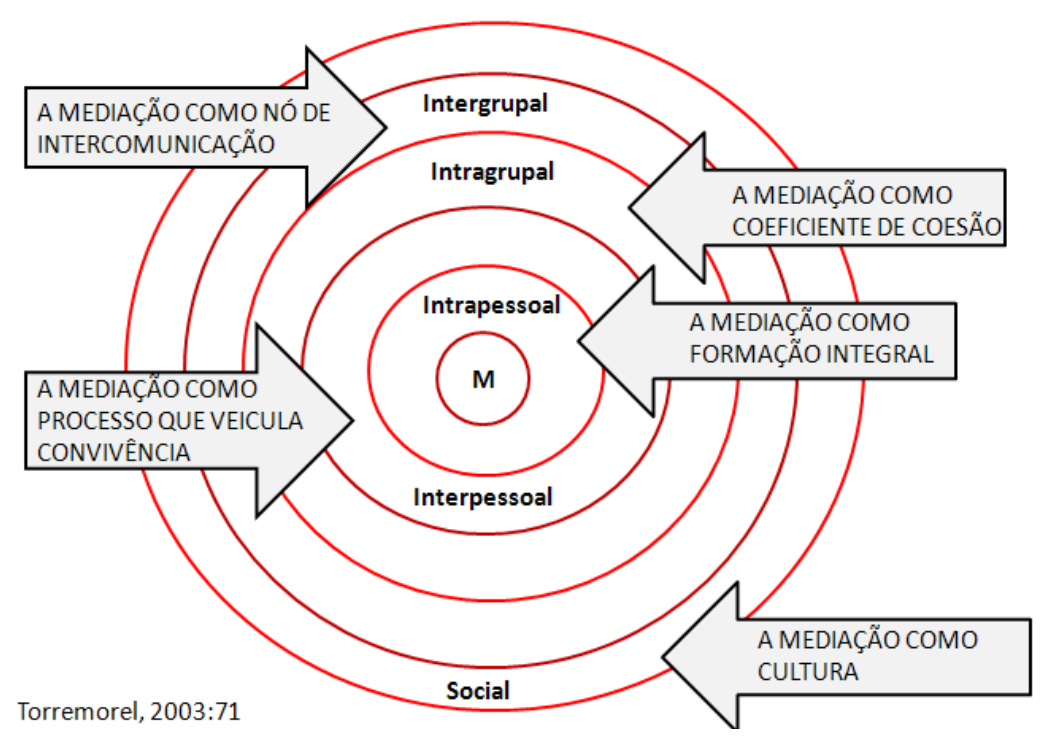

1 - Intrapessoal - formação integral, que propicia às pessoas momentos de introspecção e favorece maior consciência crítica sobre o conflito, as torna mais receptivas ao diálogo, o que implica maior compreensão e disponibilidade para ouvir e ser ouvido;

2 - Interpessoal - um processo que veicula a convivência, dá lugar à construção de laços entre as pessoas; 
3 - Intragrupal - um coeficiente de coesão entre os elementos que constituem um grupo;

4 - Intergrupal - constitui também um nó de intercomunicação entre diferentes grupos de pessoas, que estimula o intercâmbio e promove a aglutinação dos grupos em detrimento da dissociação;

5 - Social - como cultura, a mediação melhora as relações humanas, introduz reflexões individuais sobre a prática de cada um, promove a partilha de experiências e conhecimentos e acima de tudo desenvolve competências sociais imprescindíveis à vida em sociedade.

Embora o conceito ideal de mediação se confronte com limitações decorrentes da pluridimensionalidade do contexto. que faz com que se reconheça a inexistência de mediação perfeita,

"toda a mediação é um momento de catálise (...); a mediação mais conseguida, a melhor sucedida, é aquela que produz uma verdadeira comunicação entre as partes, uma comunicação que trará realmente frutos na vida de cada uma das duas pessoas ou de cada um dos dois grupos" (Six, 1990: 185).

ao impacto singular quase imediato da mediação, a sua configuração coletiva,na medida em que

"A mediação desenha um arco social que cruza todas as fronteiras culturais, económicas e étnicas, iluminando zonas conflituosas a pequena e grande escala. A missão da mediação é exactamente a de servir de ponto de encontro daqueles que são diferentes sem cair na tentação de os homogeneizar" (Torremorell, 2003: 81).

Os protagonistas do processo de mediação são sujeitos detentores de bagagens culturais e experiências únicas que participam na construção ou reconstrução das suas próprias histórias de vida, da relação com os outros e do contexto em que estão inseridos. Em contextos plurais, Santos Silva salienta que

"Dada a estrutura desigualitária da distribuição de recursos, de oportunidades e de poderes, [as] diferenças [de identidade étnica, de cultura, de padrões de comportamento e organização social] tendem a ser reconfiguradas como desigualdades, tendem a induzir ou até a justificar, assimetrias, privações e marginalizações a que os membros daqueles grupos são sujeitos. O

Mediaciones Sociales, № 12, 2013, pp. 132-157. ISSN electrónico: 1989-0494.

DOI: http://dx.doi.org/10.5209/rev_MESO.2013.n12.45266 
que dificulta ou mesmo impede a realização dos seus direitos pessoais, o desenvolvimento de sentimentos de auto-estima e respeito, a sua inserção social, familiar, laboral, profissional, cívica e a sua relação com as instituições, as normas e as rotinas da sociedade englobante" (Santos Silva, 1998: 4, in Oliveira e Galego, 2005: 33).

Se considerarmos, em acréscimo, que o próprio contexto social e político não comporta muitas vezes as condições, as oportunidades e os recursos necessários à concretização de tais direitos, transformando-os em meras garantias formais sem consequências reais e efetivas nas condições de vida das pessoas, temos necessariamente de ponderar a relevância de processos de desenvolvimento promotores de justiça e de verdadeira equivalência de oportunidades para populações diferenciadas. A capacitação, de que nos fala Amartya Sen (2003), preconiza a possibilidade de escolha como o elemento basilar de uma sociedade desenvolvida. Isto implica necessariamente a existência de estruturas e de políticas capazes de propiciar as condições para que as pessoas possam viver a vida que desejam viver (a este nível são particularmente importantes as políticas de saúde e de educação). A pobreza constitui-se assim, para este autor, não essencialmente como ausência de recursos materiais mas como ausência de liberdade. Uma pessoa que passa fome não é livre, vive aprisionada à luta pela sobrevivência, ainda que a liberdade se constitua como um princípio e um direito formalmente estruturante da sociedade em que vive. Tal modelo de avaliação do nível de desenvolvimento de uma sociedade difere do modelo de avaliação mais tradicional, que se foca apenas em variáveis como o rendimento económico. Como salienta Guilherme Marques:

"Tais liberdades substantivas são os frutos do desenvolvimento, de modo que a falta de disposições sociais e económicas, tais como os serviços de saúde e educação, limitam a actuação livre dos cidadãos, impedindo-os de se alimentarem adequadamente, adquirirem remédios e tratamentos, obterem conhecimento e instrução” (2010: 120).

Através de tais carências, um indivíduo tem a sua liberdade limitada, vivendo diante de condições degradantes, sem perspectivas de participar activamente como cidadão, na deliberação, elaboração e implementação das políticas públicas e das suas escolhas de vida. Esta é uma realidade transversal a vários contextos sociais, económicos e políticos, um panorama que encontramos espalhado nas comunidades, cada uma com a especificidade do local onde os conflitos e os problemas ganham dimensão e expressão, porque é lá que são vividos. Hoje vivemos em contextos de crise e de con-

Mediaciones Sociales, № 12, 2013, pp. 132-157. ISSN electrónico: 1989-0494. DOI: http://dx.doi.org/10.5209/rev_MESO.2013.n12.45266 
flitualidade social expressa ou latente, alocados a problemas de pobreza e exclusão social, envelhecimento populacional e decréscimo de capacidade produtiva, desemprego e precariedade laboral, endividamento dos Estados e das famílias e desajuste das políticas públicas. Os conflitos que os impulsionam ou que deles decorrem apenas se transformam, não se diluem.

\subsection{Cruzamentos analíticos na configuração de uma cultura de me- diação e de paz}

$\mathrm{O}$ risco e a incerteza são uma constante que dificulta o despertar da esperança e a identificação de oportunidades. Neste contexto, torna-se necessária uma "cultura de mediação", com uma vocação societal e que se inscreva no projecto ético-social e operativo de construção de uma cultura de paz. A mediação social ganha, aqui, especial relevância: cria condições para que o indivíduo, os grupos e as comunidades façam parte do processo de mudança de paradigma, de forma mais ou menos activa, reestruturando e construindo recursos, discutindo e determinando políticas, promovendo dinâmicas argumentativas e questionadoras do instituído, logo criando condições de emancipação pessoal e social. Tal desiderato resultará do cruzamento de 3 factores:

a) O modelo teórico de referência: Inicialmente centrado sobre o conflito, e no esgrimir de argumentos que opõem os litigantes, através de um processo de negociação assistida e facilitadora da análise e ponderação de oportunidades de resolução sem dar a face, o conceito de mediação e o processo operativo e reflexivo subjacente foi transitando de uma perspectiva curativa ou preventiva centrada no conflito e no acordo (Modelo de Harvard, Tradicional-Linear de Fisher y Ury, 1998) para uma perspectiva transformadora, associada ao crescimento pessoal, e à construção e restauração de laços sociais, imprimindo à mediação uma dinâmica transformadora na forma de pensar e de agir. Falamos do modelo transformativo centrado no relacionamento e nos protagonistas (Folger, 2007; Folger e Bush, 1999), e no modelo circular-narrativo (Cobb, 1997) centrado no processo e conteúdos, na reconstrução de narrativas, ou como refere Suarez "centrado tanto nas relações como nos acordos" (1997: 63). Como refere Dora Fried Schnitman, compreende-se

“a evolução de um conflito focalizando não só as emoções, intenções e crenças dos participantes, mas também os domínios simbólicos, as cons-

Mediaciones Sociales, № 12, 2013, pp. 132-157. ISSN electrónico: 1989-0494. DOI: http://dx.doi.org/10.5209/rev_MESO.2013.n12.45266 
truções narrativas, as tramas dialógicas que constroem e transformam significados e práticas, projetos e resultados" (Schnitman, 1999: 21).

Os novos paradigmas de mediação apoiam-se na noção de construção social da realidade, em que observador é um sujeito reflexivo e coconstrutor dessa realidade; Com base nestes pressupostos, fornecem perspectivas renovadas para a participação dos atores sociais, aumentando as suas capacidades de transformação pela ação e de confronto / resolução de conflitos e dilemas, proporcionando novas leituras e uma maior consciência sobre a importância da sua implicação na construção do futuro.

b) As competências do mediador: $\mathrm{O}$ desenvolvimento do processo catalítico que propicia a construção de uma nova perspectiva analítica e de acção, explora a possivel reconfiguração das diferenças argumentativas e a configuração de resultados marcados pelo formato processual ganhadorganhador, em vez do tradicional ganhador-perdedor. A solução configura uma alternativa que, por ser partilhada e estabelecida num clima de confiança e responsabilidade, é desenhada por medida, tomando por objecto o possível (as capacidades e competências do mediador e dos mediados, os recursos disponíveis ou acessíveis, o jogo entre oportunidades e constrangimentos). Todo o processo comunicacional estabelecido pressupõe competências a nível teórico, prático e axiológico, que se adquirem num diálogo permanente entre estas 3 dimensões do conhecimento, em contexto de formação, de prática reflexiva e de supervisão.

Os novos paradigmas e as condições contemporâneas propoem cenários alternativos de inteligibilidade da mudança e neles se configuram temas centrais para a forma como se produz a gestão dos conflitos: 1 - o abandono da ideia de défice; 2 - o direccionamento para processos que reconhecem as perspectivas, as oportunidades, as esperanças e as expectativas, como fonte de abertura à construção do novo e imprevisto; 3 - a promoção de mudanças pela ênfase numa comunicação positivamente valorativa do existente; 4 - o trabalho prospectivo e a importância da criatividade; 5 - a restauração do papel activo das pessoas na construção da realidade; 6 - o papel das flutuações, da não linearidade, da desordem e do desequilíbrio na construção de alternativas; 7 - o reconhecimento do poder relativo de pequenas flutuações serem susceptíveis de gerar mudanças em escala; 8 - a importância da comunicação, entendida como sistema em coevolução, e não como um modelo linear de causa-efeito. A racionalidade construtiva do diálogo transforma a maneira de entender a resolução dos

Mediaciones Sociales, № 12, 2013, pp. 132-157. ISSN electrónico: 1989-0494. DOI: http://dx.doi.org/10.5209/rev_MESO.2013.n12.45266 
conflitos, ultrapassando a perspectiva redutora de aplicação de técnicas, no sentido da afirmação da importância do enquadramento dos problemas, da sua interpretação e definição. Esta é uma condição fundamental para o desenvolvimento do processo e a promoção de mudança a nível pessoal, social e político. Como salientam Oliver Ramsbotham, Tom Woodhouse e Hugh Mial "muchos de los conflictos actuales si no la mayoria, surgen de la incapacidad de las instituciones politicas, economicas y sociales para prestar una atención suficiente a los agravios y las necessidades percibidas de grupos importantes de la población” (1997: 33).

c) O Contexto - natureza e complexidade do conflito: As perspectivas analíticas dominantes sobre os conflitos estão muito centradas na diferenciação dinâmica e funcional dos processos de desenvolvimento humano e social, que parametrizam as divergências em subcategorias: conflitos psicológicos, sociais, políticos e económicos. Para Rittel e Webber (1973) as decisões públicas lidam com problemas "perversos" (wicked) e diferentes na medida em que, não existe a formulação definitiva de um problema; este não está limitado temporalmente; não existe nenhuma solução imediata nem tampouco um leque de soluções potenciais. Um problema constitui um sintoma de um outro problema; existem explicações diversas e a escolha de uma delas condiciona a natureza da solução. Estas características potenciam a emergência de conflitos com dificuldade de solução acrescida e que envolvem a auscultação e participação de diversos stakeholders.

Caser e Vasconcelos definem os seguintes critérios para identificar potenciais conflitos complexos:

"Acordo reduzido quanto ao problema; Incerteza face aos factos, métodos e futuro; Informação técnica multidisciplinar; Muito conhecimento prático; Muitos valores e interesses; Muitos participantes (mediados) com poder e competência desigual; Soluções requerendo ações coordenadas; Sensação de não haver solução satisfatória" (2008: 35).

Esta complexidade constitui um desafio para os decisores não apenas no domínio público, mas também privado. Segundo as autoras, a Mediação Multipartes Complexa constitui o processo mais indicado nestes casos. Comparativamente à mediação bilateral (familiar, penal, de consumo,...), a mediação multipartes distingue-se pelo seu potencial de empowerment (individual e coletivo) e de participação em rede de diferentes stakeholders. O processo de mediação é muito mais flexível, os objetivos são mais amplos, e a 
gestão do conflito tem uma lógica potencialmente transformadora de consciências, de responsabilidades, de conhecimentos e competências, dando luz verde a processos inovadores de valor acrescentado a nível político e social.

A mediação social não se esgota, pois, no uso da palavra pacificadora. $\mathrm{O}$ mediador é um facilitador, mas também um construtor da sinergia necessária ao processo de mudança social e ao exercício da cidadania. De acordo com Almeida (2001), espera-se que a mediação profissional no domínio social permita igualmente aos cidadãos aceder aos serviços (promoção de acessibilidades), participar em grupos de pares (facilitar a sociabilidade), potenciar a aquisição de competências (apoiar, informar e incentivar à formação), aumentar o seu potencial reflexivo e dinamizador (promover, motivar, dinamizar, favorecer um maior nível de consciencialização). A mediação social implica ainda a construção de alternativas que estimulem e envolvam a responsabilidade dos poderes públicos e a legitimidade de ingerência social da sociedade civil, através do diálogo, ultrapassando muitas vezes as expectativas dos próprios cidadãos. A mediação promove a esperança, gere e impulsiona responsabilidades a nível político, social e pessoal. Deste modo, a mediação cumpre o seu papel na construção de conexões, potencia vínculos e revela-se um modo de intervenção impulsionador de mudanças internas (nas pessoas) e externas (nas organizações, nas políticas e nas acções dos stakeholders), edificando uma teia de recursos (materiais e simbólicos) capaz de integrar profissionais, utentes, voluntários, organizações, decisores políticos, cuja articulação constitui uma mais-valia no processo de desenvolvimento social (Tabla 1). Por isso se pode afirmar que a Mediação Social é no mínimo trial (característica comum a qualquer processo de mediação), podendo configurar-se como um polo processual dinâmico, simultaneamente agregador e impulsionador de articulação multipartes.

É no cruzamento analítico dos ideais da cultura de mediação com os da cultura de paz que se posiciona a concepção e a prática de Mediação Social, cooptando a perspectiva de regulação do conflito, no âmbito do direito de ingerência social que caracteriza a mediação, com o devir ético, político e social da paz (Tabla 1).

Tabla 1. Cultura de mediação e cultura de paz - cruzamentos analíticos na conceptualização da mediação social

\begin{tabular}{c|c|c}
\hline \hline Cultura de mediação & Mediação social & Cultura de paz \\
\hline \hline
\end{tabular}

Mediaciones Sociales, № 12, 2013, pp. 132-157. ISSN electrónico: 1989-0494. DOI: http://dx.doi.org/10.5209/rev_MESO.2013.n12.45266 


\begin{tabular}{|c|c|c|}
\hline $\begin{array}{l}\text { Precursora e promotora de } \\
\text { um direito de ingerência } \\
\text { social }\end{array}$ & $\begin{array}{l}\text { Modo alternativo de resolu- } \\
\text { ção de conflitos } \\
\text { Conceção e modelo de Inter- } \\
\text { venção Social, que se inscre- } \\
\text { ve no projeto ético-social } \\
\text { político e operativo de cons- } \\
\text { trução de uma cultura de } \\
\text { paz. }\end{array}$ & Devir ético, político e social \\
\hline $\begin{array}{l}\text { - Aloca fundamentos éticos } \\
\text { de respeito pela dignidade } \\
\text { humana, pela diferença e } \\
\text { cidadania, através de pro- } \\
\text { cessos participativos e } \\
\text { democráticos } \\
\text { - Sustenta modalidades } \\
\text { alternativas de gestão das } \\
\text { relações sociais, tornando- } \\
\text { se um processo comunicaci- } \\
\text { onal de transformação do } \\
\text { social e uma requalificação } \\
\text { das relações sociais. }\end{array}$ & $\begin{array}{l}\text { - Processo ancorado em } \\
\text { valores, designadamente o } \\
\text { respeito pelos direitos hu- } \\
\text { manos e liberdades funda- } \\
\text { mentais, a cidadania, a } \\
\text { cooperação, a não discrimi- } \\
\text { nação, a tolerância e a soli- } \\
\text { dariedade. } \\
\text { - Potencia a construção de } \\
\text { conexões e de vínculos } \\
\text { - Impulsiona mudanças } \\
\text { internas (nas pessoas) e } \\
\text { externas (nas organizações, } \\
\text { nas políticas e nas ações dos } \\
\text { stakeholders) } \\
\text { - Edifica uma rede de supor- } \\
\text { te capaz de integrar profis- } \\
\text { sionais, utentes, voluntários, } \\
\text { organizações, decisores } \\
\text { políticos, cuja articulação } \\
\text { constitui uma mais-valia no } \\
\text { processo de desenvolvimen- } \\
\text { to social. }\end{array}$ & $\begin{array}{l}\text { - Preconiza uma sociedade } \\
\text { sustentada em valores e } \\
\text { procedimentos democráti- } \\
\text { cos: o respeito pelos direitos } \\
\text { humanos e liberdades fun- } \\
\text { damentais, a cidadania, a } \\
\text { cooperação, a não discrimi- } \\
\text { nação, a tolerância e a } \\
\text { solidariedade. } \\
\text { - Possui um potencial trans- } \\
\text { formador dos fatores de } \\
\text { risco numa dinâmica de } \\
\text { sinergias abertas à muda- } \\
\text { nça. }\end{array}$ \\
\hline
\end{tabular}

Elaboração das autoras (2012)

\section{Considerações Finais}

Como Martin Griffiths afirma no Relatório "10 Years. Mediation for Peace 1999-2009”, a construção da paz está dominada pelas decisões dos homens, tanto dos mediadores como dos litigantes. No entanto, ela pode ser limitada ou potenciada pelas dinâmicas das organizações e das comunidades onde aqueles estão integrados (estrutura económica e política, valores culturais, recursos materiais e humanos, movimentos associativos, entre outros aspectos). 
A mediação social é em si um poderoso instrumento porque favorece a coesão social, cria e potencia relações coesas entre os indivíduos, os recursos e as dinâmicas ambientais. Deste modo, amplia a capacidade de conhecer e agir em conformidade com os interesses e respeito pelos direitos e deveres de cada pessoa e cidadão. É certo que a cultura da mediação em Portugal não está devidamente difundida e apreendida quer pelos órgãos políticos, potenciais preventores, quer pela população em geral, potenciais difusores e beneficiários. No entanto, a multiplicidade de experiências de mediação no campo familiar, educativo, penal, laboral, sócio-cultural, comunitário e social e a diversidade de mediadores (profissionais e cidadãos) com perfis e formações tão diversas (mediadores especializados, educadores, sociólogos, assistentes sociais, voluntários,...) permite-nos configurar a mediação como modelo integrado de intervenção social e como motor de uma cultura de paz.

“A mediação e a cultura que lhe está associada, caracterizada pelo respeito para com o "outro", a focalização no diálogo, a valorização da cidadania, a importância atribuída aos sujeitos e ao desenvolvimento das suas competências no processo de mudança, a esperança numa solução que ultrapasse o binómio "ganhador-perdedor", e que é transversal a todo o processo relacional, constituem um mais-valia no "recosimento" dos laços sociais em ruptura" (Almeida, 2009:118).

Por outro lado, como salienta Torremorell "A cultura de mediação, em si, deverá passar por um processo de construção fundamentado na interrogação e na reflexão colectivas em torno das situações conflituosas, que são as que nos interpelam" (2003: 86).

Neste sentido, a criação de condições estruturais que possibilitem a concretização (substancial e não apenas formal) da igualdade de oportunidades implica a efectivação de processos de mediação entre níveis de decisão (local, nacional, global), níveis de intervenção (micro,meso,macro) e dimensões (individuais e colectivas). Colocar em relação estes diferentes vectores, numa perspectiva comunicacional, operativa e política, constituise como um pressuposto de construção da paz. Incentivar a capacitação e a proactividade dos indivíduos e em paralelo desenvolver os recursos e respostas associados às estruturas de oportunidades, articular o "querer" com o "ter a possibilidade de (...)", constitui-se como o pilar fundamental do desenvolvimento e da paz a ele associado. Ninguém é livre passando fome (Sen, 2003). Deste modo, o combate às desigualdades, à pobreza e a todas 
as formas restritivas da liberdade de ser, de estar e de agir são essenciais na promoção de um projecto ético de paz, de democracia e de desenvolvimento. É sob este pressuposto aliás que Muhamad Yunnus ganha o prémio Nobel da Paz em 2006.

Torna-se necessário dar voz a novas formas de enfrentar os constrangimentos, novos modos de agir face à diferença, centradas na tolerância, mas também nas forças, no sentido de oportunidade e de empowerment individual e colectivo. Tal implica a construção de alternativas, que, como refere Urie Bronfenbrenner (1996), recusam o modelo de "défice", aspecto igualmente salientado por Dora Schnitman (1999), a ideia de fatalismo funcional e social (Lascoux, 2001), dando lugar à procura, criação e promoção de estruturas de oportunidade. A mediação para além de uma dimensão humana e pacificadora, possui dimensões (estratégicas e políticas, pedagógicas e práticas) comprometidas com experiências transformadoras que favorecem o desenvolvimento humano e promovem a cidadania, e neste sentido traduz uma nova capacidade de ver e compreender o mundo e de nele intervir.

\section{Bibliografía}

Almeida, H. (2001): Conceptions et Pratiques de la Médiation Sociale. Les modèles de médiation dans le quotidien professionnel des assistants sociaux. Coimbra: Fundação Bissaya-Barreto/Instituto Superior Bissaya-Barreto.

Almeida, H. (2009): "Um panorama das mediações nas sociedades. Na senda da construção de sentido da mediação em contexto educativo", in VEIGA S. et al. (orgs.): Tutoria e Mediação em Educação. Lisboa: EDUCA.

Bonafé-SCHMitT, J.P. (1988): "Plaidoyer pour une sociologie de la médiation" in Annales de Vaucresson, 29, pp.19-44.

BONAFÉ-SCHMITT, J.P. et al. (1992a): Médiation et régulation sociale. Lyon: GLSI Université Lyon II.

Bonafé-SchmitT, J.P. (1992b) : La Médiation: une justice douce. Paris: Syros.

Bronfenbrenner, U. (1996): A ecologia do desenvolvimento humano: experimentos naturais e planejados. Porto Alegre: Artes Médicas. 
Burton, J. (1990): Conflict: Resolution and Provention. New York: St. Martin's Press, Inc.

CASER, URsula E VASCONCElos, L. (2008): “A mediação multipartes e os desafios e potencialidades da mediação urbana”, in VASCONCELOS-SOUSA, J. (coord./ed.): Campos da mediação. Novios caminhos, novos desafios. Coimbra: Mediarcom/Minerva, pp. 33-40.

Centre for Humanitarian Dialogue (1999-2009): “10 Years. Mediation for Peace”, Mediation For Peacer Disponível em http://www.operationspaix.net/IMG/pdf/CHD_MediationForPeace_19992009. pdf. Consultado em 15 abril 2010.

COBB, S. (1997): “Una perspectiva narrativa en mediación”, in FoLGER, J. P. y JONES, T. S. (compiladores): Nuevas direcciones en mediación. Investigación y perspectivas comunicacionales. Buenos Aires: Paidós Mediación, $\mathrm{n}^{\mathrm{o}} 7,1^{\mathrm{a}}$ edición.

Declaração para Uma Cultura de Paz - Resolução 52/243 da Assembleia Geral das Nações Unidas, de 6 de Outubro de 1999.

Fisher, R., URy, W. y PAtTon, B.M. (1998, 2000: 4ª edición): Obtenga el Sí: el arte de negociar sin ceder. Barcelona: Gestión.

FISCHER, T. (1987): “Towards a Model of Co-Working in Family Conciliation”, The British Journal of Socail Work. Reino Unido: Lancaster.

FOLBERG, J.P.(2007): "Mediación Transformativa: Preservación del potencial único de la mediación en situaciones de dispuestas”, Revista de Mediación, $\mathrm{n}^{\circ} 2$. Especial modelo transformativo. Madrid: Asociación Madrileña de Mediación.

Folger, J.P. y Bush, R.B. (1999): "Mediação Transformativa e Intervenção de erceiros: as Marcas Registradas de um Profissional Transformador”, in SCHNITMan, D.F. e Littlejohn, S. (orgs): Novos Paradigmas em Mediação. São Paulo: Editores Artes Médicas Sul, pp. 85-100.

FONKERT, R. (1999): "Mediação Familiar: Recurso Alternativo à Terapia Familiar na Resolução de Conflitos em Famílias com Adolescentes”, in Schnitman, D.F. e Littlejohn, S. (orgs): Novos Paradigmas em Mediação. São Paulo: Editores Artes Médicas Sul, pp. 169-184.

LASCOUX, J.L. (2001): Pratique de la médiation. Une métode alternative à la résolution des conflits. Col. Formation Permanente, Sémináires Mucchielle, Paris: ESF.

LEAndro, M.E. (Coord.) (2011): Laços Familiares e Sociais. Viseu: Psico\& Soma - 
Livraria, Editora, Formação e Empresas, Lda.

Levinas, E. (1991): Autrement qu'être ou au-delà de l'essence. Paris: Le Livre de Poche.

Lipovetsky, G. (2010): O Crepúsculo do Dever. Lisboa: Dom Quixote.

MARQues, G. (2010): "Analisando o desenvolvimento: a perspectiva de Amartya Sem”, Revista Urutágua - académica multidisciplinar, DCS/UEM, n 22, pp. 120123.

Oliveira, A. y Galego, C. (2005): Mediação Sócio-Cultural: Um Puzzle em Construção, Observatório da Imigração: 14. Lisboa: ACIME.

Oliverra, M.G. (2005): Mediación Comunitaria: Bases para implementar un Centro Municipal de Mediación Comunitaria y de Resolución de Conflictos. Buenos Aires: Espacio Editorial, pp. 65-79.

Ramsbotham, Oliver, Woodhouse, Tom y Miall, H. (2011): Resolución de conflitos. La prevención, gestión y transformación de conflitos letales. Barcelona: Edicions Bellaterra, S.L.

Rittel, H.W.J. y Webber, M.M. (1973): "Dilemas in a General Theory Planning", Policy Sciences, 4, pp. 155-169.

SALVÁ, S.F. (2010, $4^{\mathrm{a}}$ impression): Gestión de conflitos: taller de mediación. Un enfoque socioafectivo. Barcelona: Ariel.

SANTos Silva, A. (1998): “A Formação e a acção de mediadores sociais”, síntese de mesa redonda, organizada pelo Ministério da Educação em 27 de Março de 1998, in Oliveira, A. y Galego, C. (2005): Mediação Sócio-Cultural: Um Puzzle em Construção, Observatório da Imigração: 14. Lisboa: ACIME.

Schnitman, D.F. (1999): "Novos Paradigmas na Resolução de Conflitos", in DoRA F.S. e Stephen LitTlejohn (orgs): Novos Paradigmas em Mediação. São Paulo: Editores Artes Médicas Sul, pp. 17-27.

SEN, A. (2003): O desenvolvimento como liberdade. Lisboa: Gradiva.

Six, J.F. (1990): Le Temps des Médiateurs. Paris: Éditions du Seuil.

Six, J.F. (1995): Dynamique de la médiation. Paris: Desclée de Brower.

Torremorell, M.C.B. (2008): Cultura de Mediação e Mudança Social. Porto: Porto 


\section{Editora.}

Turrel, P. (1995): "Vers un droit d'ingérence sociale”, in SIX, J.F.: Dynamique de la médiation. Paris: Desclée de Brower, p.147.

Vasconcelos-Sousa, J. (coord/ed.) (2008): Campos da Mediação. Novos caminhos, novos desafios. Coimbra: Madiarcom/Minerva Coimbra.

Verrin, J. (1988) : "Le potentiel de la médiation”, Annales de Vaucresson, 2, n²9, pp. 201-206.

\section{PARA CITAR ESTE TRABAJO EN BIBLIOGRAFÍAS:}

ALMEIDA, H.N., PINTO ALBUQUERQUE, C. Y CRUZ SANTOS, C. (2013): "Cultura de Paz e Mediação Social. Fundamentos para a construção de uma sociedade mais justa e participativa", Mediaciones Sociales. Revista de Ciencias Sociales $y$ de la Comunicación, $\mathrm{n}^{\mathrm{o}}$ 12, pp. 132-157. DOI: http://dx.doi.org/10.5209/rev_MESO.2013.n12.45266 


\section{Los autores}

(*) Helena Neves Almeida, Phd em Trabalho Social pela Universidade de Fribourg (Suiça), com especialização em "Mediação Social". Atualmente é professora da Faculdade de Psicologia e de Ciências da Educação da Universidade de Coimbra, coordinadora da licenciatura em Serviço Social e do Mestrado em Intervenção Social, Inovação e Empreendedorismo. É autora de várias publicações no campo das Teorias e Metodologias de Intervenção e Investigação em Serviço Social, Mediação Social, Escolar e Comunitária, Empreendedorismo Social, Intervenção Social na área do envelhecimento, saúde, educação formal e informal, família e juventude É consultora Senior de Mediação Social e Comunitária, e Coordenadora do Observatório da Cidadania e da Intervenção Social e Investigadora associada no Centro de Estudos de Sociologia da Universidade de Lisboa (CESNOVA)

${ }^{(* *)}$ Cristina Pinto Alburquerque, Phd em Trabalho Social e Política Social pela Universidade de Fribourg (Suiça). Atualmente é professora da Faculdade de Psicologia e de Ciências da Educação da Universidade de Coimbra, na licenciatura em Serviço Social e no Mestrado em Intervenção Social, Inovação e Empreendedorismo. É autora de várias publicações nos campos da Política Social, Desenvolvimento Social, Empreendedorismo, Ética e Justiça Social. Investigadora no Centro de Estudos de Sociologia da Universidade de Lisboa (CESNOVA), onde é responsável pelo grupo de Investigação de Políticas Públicas e Responsabilidade Social.

${ }^{(* * *)}$ Clara Cruz Santos, doutorada em Serviço Social pela Universidade Católica de Lisboa, docente da Faculdade de Psicologia e Ciências de Educação da Universidade de Coimbra. É autora de dois livos na área de Serviço Social e Identidade Profissional, com publicações em revistas cientificas, enfatizando os aspetos da Intervenção Social e Prática Profissional do Serviço Social. É ainda Terapeuta Familiar e Mediadora Familiar.

RECIBIDO: 23 de noviembre de 2012.

ACEPTADO: 18 de marzo de 2013. 